\title{
Serotonin and the Control of Ventilation in Awake Rats
}

\author{
E. B. Olson, JR., J. A. Dempsey, and D. R. McCrimmon, Department of \\ Preventive Medicine, University of Wisconsin, Madison, Wisconsin 53706
}

\begin{abstract}
A B S T R A C T In awake, unrestrained, intact rats, reserpine, para-chlorophenylalanine, 6-fluorotryptophan, and para-chloroamphetamine depleted whole brain serotonin and produced a substantial and sustained hyperventilation as evidenced by a 5-9 torr drop in $\mathrm{Pa}_{\mathrm{CO}_{2}}$. Administration of 5-hydroxytryptophan to rats treated with para-chlorophenylalanine partially alleviated the hyperventilation. No change in ventilation was observed after alpha-methyltyrosine. 5,7Dihydroxytryptamine produced contradictory results. On the basis of these pharmacological studies, we propose that some serotonin-mediated nerve transmissions might function under physiological conditions to inhibit the central nervous system output which controls normal breathing.
\end{abstract}

\section{INTRODUCTION}

Under steady-state circumstances, in a wide range of conditions, involuntary respiration is exquisitely regulated to balance the uptake of oxygen and release of carbon dioxide with the rate of metabolism. The neurohumoral agents involved in maintaining this overall control of ventilation are incompletely understood. We used a spectrum of pharmacological agents to systematically explore a correlation between breathing and the metabolism of the monoamine neurotransmitters, norepinephrine (NE), ${ }^{1}$ dopamine (DA), and serotonin (5-hydroxytryptamine, 5HT).

Other researchers have measured changes in ventilation of decerebrate or intact anesthetized cats treated with drugs that alter monoamine metabolism. They concluded that an increase in serotonin levels in the brainstem has a depressant influence on respiratory mechanisms $(1,2)$.

The use of decerebrate, anesthetized, or analgesic-

\footnotetext{
Received for publication 12 April 1979 and in revised form 17 May 1979.

${ }^{1}$ Abbreviations used in this paper: AMT, alpha-methyltyrosine; DA, dopamine; 5,7-DHT, 5,7-dihydroxytryptamine; 6-FT, 6-fluorotryptophan; 5HT, 5-hydroxytryptamine; NE, norepinephrine; PCA, para-chloroamphetamine; PCPA, para-chlorophenylalanine.
}

treated animals, although necessary for many of the techniques used to measure ventilation, is open to the criticism that sedation may in itself influence breathing and ventilatory control $(3,4)$. We have shown that the laboratory rat is an animal model suitable for ventilatory studies in the conscious, unrestrained state, and that the rat, unlike most other species, shows the essential characteristics of ventilatory adaptation to chronic hypoxia observed in man (5).

\section{METHODS}

To examine the effect of monoamine neurotransmitter metabolism on eupneic ventilation, adult male albino rats of the Sprague-Dawley strain were treated with one of several drug regimens which alter monoamine metabolism (Table I). For each drug treatment, control rats were injected with an equal volume of the specific drug's carrier vehicle and were measured at the times indicated in Table I. In no instance, including intracerebroventricular injections, did the vehicle injections cause a change in measurements of ventilation, blood gases, or brain neurotransmitter levels. As expected, we observed a transient hyperactivity after 5,7-dihydroxytryptamine (5,7-DHT) and subdued or unchanged activity following the other pharmaceutical agents (8).

In our experiments, breathing frequency and tidal volume were monitored within a whole body plethysmograph apparatus. Simultaneously, arterial blood was withdrawn with a chronically indwelling femoral artery catheter. Oxygen consumption of each rat was then directly measured by spirometry. The accuracy and technical details of this methodology have been described previously (5). After an appropriate interval, the animals were killed by decapitation; within $1 \mathrm{~min}$ their brains were removed and placed in liquid nitrogen. Whole brain analysis of NE, DA, and 5HT was performed after acid-butanol extraction, using cation exchange high performance liquid chromatography with electrochemical detection, essentially as outlined by Sasa and Blank (12). Arterial blood gases and acid-base status as well as expired ventilation and oxygen consumption were determined under control conditions for each rat. Control rats were sacrificed on the same day as treated rats for brain analysis. The overall data obtained under control conditions are presented in the first line of Table II. In every group the carrier control ventilation measurements were within overall control experience. Brain neurotransmitter levels appear to undergo a cyclical variability. The results of brain analysis are therefore expressed as the percent differences of treated rats' brains relative to values from an equal number of control brains analyzed in parallel. 
TABLE I

Blocking Agents Used in the Study of Ventilatory Control and Central Nervous System Neurotransmitters

\begin{tabular}{|c|c|c|c|}
\hline Drug & Dose and route of administration & $\begin{array}{l}\text { Time after } \\
\text { dose }\end{array}$ & Mode of action \\
\hline Reserpine & $5 \mathrm{mg} / \mathrm{kg}$ i.m. as serpasil & $2 \mathrm{~d}$ & Prevents storage of monoamine neurotransmitters (6) \\
\hline PCPA & $\begin{array}{l}300 \mathrm{mg} / \mathrm{kg} \text { i.p. suspended in } \mathrm{pH} 2,1 \mathrm{~N} \\
\mathrm{HCl}\end{array}$ & $2 \mathrm{~d}$ & Inhibits tryptophan hydroxylase (7) \\
\hline AMT & $300 \mathrm{mg} / \mathrm{kg}$ i.p. in $\mathrm{pH} 10-11$ saline & $\begin{array}{c}5 \mathrm{~h} \text { average } \\
(1-13 \mathrm{~h})\end{array}$ & Inhibits tyrosine hydroxylase $(8)$ \\
\hline 6-FT & $100 \mathrm{mg} / \mathrm{kg}$ i.p. in pH 9-10 saline & $4 \mathrm{~h}$ & Inhibits tryptophan hydroxylase (9) \\
\hline PCA & $5 \mathrm{mg} / \mathrm{kg}$ i.p. in saline & $2 \mathrm{~d}$ & $\begin{array}{l}\text { Releases serotonin }(5 \mathrm{HT}) \text {, inhibits tryptophan } \\
\text { hydroxylase, serotonergic neurotoxicity }(6,10)\end{array}$ \\
\hline 5,7-DHT & $\begin{array}{l}80-200 \mu \mathrm{g} \text { in } 20 \mu \mathrm{l} \text { saline }+0.1 \% \\
\text { ascorbate intracerebroventricu- } \\
\text { larly } 1 \mathrm{~h} \text { after desipramine } 25 \\
\mathrm{mg} / \mathrm{kg} \text { i.p. in saline }\end{array}$ & $10-18 \mathrm{~d}$ & Cytotoxic for nerve cells containing serotonin (11) \\
\hline
\end{tabular}

\section{RESULTS AND DISCUSSION}

We measured $\mathrm{Pa}_{\mathrm{CO}_{2}}, \mathrm{pHa}$, and $\dot{\mathrm{V}} \mathrm{E}: \dot{\mathrm{VO}}_{2}$ as quantitative indicators of a ventilatory response to pharmacological alterations in monoamine neurotransmitter metabolism. Classically, hyperventilation is defined as a relative increase in alveolar ventilation over metabolic $\mathrm{CO}_{2}$ production resulting in a reduction in alveolar and arterial carbon dioxide tensions. A chronic decrease in $\mathrm{Pa}_{\mathrm{CO}_{2}}$ results in an increase in arterial $\mathrm{pH}$ and a compensatory fall in $\left[\mathrm{HCO}_{\overline{3}}\right] \mathrm{a}$, i.e. chronic respiratory alkalosis. The relative magnitude of a ventilatory change is also reflected in a change of the $\dot{\mathrm{V} E}: \dot{\mathrm{VO}}_{2}$ ratio. An increase in this ratio indicates that expired ventilation has increased relative to any change in metabolic rate. The changes in the ventila- tory parameters $\left(\mathrm{Pa}_{\mathrm{CO}_{2}}, \mathrm{pHa}\right.$, and $\left.\dot{\mathrm{V}}_{\mathrm{E}}: \dot{\mathrm{VO}}_{2}\right)$ as well as the relative changes in whole brain $\mathrm{NE}, \mathrm{DA}$, and 5HT levels produced by each of the neurotransmitteraltering drug regimens are listed in Table II.

After $2 \mathrm{~d}$, reserpine produced a profound depression in whole brain levels of all three monoamines. This resulted in a substantial hyperventilation as evidenced by a drop in $\mathrm{Pa}_{\mathrm{CO}_{2}}$ of over 8 torr. The failure to observe a change in the $\dot{\mathrm{V}}: \dot{\mathrm{V}} \mathrm{O}_{2}$ ratio may be explained by a reduction in dead space, making $\dot{V}_{A}$ a larger fraction of $\dot{V} E$. Consistent with this explanation, reserpine treatment produced an increase in tidal volume with no change in breathing frequency. The chronic hyperventilation did produce an increase in $\mathrm{pHa}$ and was partially compensated by a $2.4-\mathrm{meq} / \mathrm{liter} \mathrm{de}-$ crease in $\left[\mathrm{HCO}_{\overline{3}}\right] \mathrm{a}$.

TABLE II

Effects of Pharmacologic Blockade on Ventilation and Brain NE, DA, and 5HT Concentrations (Mean $\pm 95 \%$ confidence limits [ number treated])

\begin{tabular}{|c|c|c|c|c|c|c|}
\hline & $\mathrm{PacO}_{2}$ & $\mathrm{pHa}$ & $\dot{\mathrm{V}} \mathbf{E}: \dot{\mathrm{VO}}_{2}$ & NE & DA & $5 \mathrm{HT}$ \\
\hline \multirow{3}{*}{$\begin{array}{l}\text { Overall control } \\
\qquad(n=83)\end{array}$} & $m m \mathrm{Hg}$ & & & \multicolumn{3}{|c|}{$n g / g$} \\
\hline & $39.9 \pm 0.3$ & $7.435 \pm 0.002$ & $30.2 \pm 0.8$ & $791 \pm 37$ & $891 \pm 54$ & $627 \pm 31$ \\
\hline & \multicolumn{3}{|c|}{ Change from carrier controls } & \multicolumn{3}{|c|}{ Percent depletion from carrier controls } \\
\hline Reserpine & $-8.8 \pm 3.4(6)^{*}$ & $0.04 \pm 0.02(6)^{*}$ & $0.2 \pm 10.7(6)$ & $-91 \pm 8(3)^{*}$ & $-91 \pm 32(3)^{*}$ & $-86 \pm 20(3)^{*}$ \\
\hline PCPA & $-7.2 \pm 0.8(30)^{*}$ & $0.04 \pm 0.01(29)^{*}$ & $5.0 \pm 3.0(12) \ddagger$ & $-22 \pm 11(8) \ddagger$ & $4 \pm 16(8)$ & $-76 \pm 15(8)^{*}$ \\
\hline AMT & $-0.3 \pm 2.1(5)$ & $0.02 \pm 0.03(5)$ & $4.4 \pm 5.9(6)$ & $-86 \pm 5(15)^{*}$ & $-73 \pm 6(15)^{*}$ & $63 \pm 14(15)^{*}$ \\
\hline 6-FT & $-5.9 \pm 1.4(11)^{*}$ & $0.06 \pm 0.01(11)^{*}$ & $4.0 \pm 3.6(10) \ddagger$ & $-2 \pm 6(5)$ & $-4 \pm 9(5)$ & $-40 \pm 10(5)^{*}$ \\
\hline PCA & $-5.4 \pm 1.1(8)^{*}$ & $0.02 \pm 0.03(8)$ & $4.3 \pm 4.2(8) \ddagger$ & $-4 \pm 13(5)$ & $-1 \pm 5(5)$ & $-51 \pm 14(5)^{*}$ \\
\hline 5,7-DHT & $2.1 \pm 1.5(10) \ddagger$ & $0.01 \pm 0.01(10)$ & $-0.9 \pm 2.7(10)$ & $9 \pm 8(20) \ddagger$ & $-16 \pm 13(20) \ddagger$ & $-60 \pm 11(20)^{*}$ \\
\hline
\end{tabular}

$* P<0.01$.

$\$ P<0.05$. 
In another series of experiments para-chlorophenylalanine (PCPA), an inhibitor of tryptophan hydroxylase (7), produced a reduction in whole brain serotonin of over $70 \%$. However, PCPA also reduced NE $22 \%$ while leaving DA levels unchanged. After $2 \mathrm{~d}$, PCPA treatment resulted in a pronounced hyperventilation as evidenced by a 7-torr reduction in $\mathrm{Pa}_{\mathrm{CO}_{2}}$ and a $16 \%$ elevation in the $\dot{\mathrm{V}} \mathrm{E}: \dot{\mathrm{V}}_{2}$ ratio. This hyperventilation was reflected by a $2.5-\mathrm{meq} / \mathrm{liter}$ reduction of $\left[\mathrm{HCO}_{\overline{3}}\right] \mathrm{a}$ and an alkalotic arterial $\mathrm{pH}$. The increased $\dot{\mathrm{V}} \mathrm{E}$ was the result of a $25 \%$ increase in tidal volume. The results of PCPA treatment suggest the involvement of either $\mathrm{NE}$ or $5 \mathrm{HT}$ metabolism in ventilatory control.

Alpha-methyltyrosine (AMT), an inhibitor of tyrosine hydroxylase $(8)$, produced a $>70 \%$ reduction in whole brain levels of the catecholamines, NE and DA. Unexpectedly, AMT treatment also resulted in an increase in whole brain $5 \mathrm{HT}$ of over $60 \%$. Spector et al. (13) reported no effect of repeated doses of AMT $(80 \mathrm{mg} / \mathrm{kg}$ every $3 \mathrm{~h}$ for $24 \mathrm{~h}$ ) on guinea pig brainstem 5HT levels. The reasons for this discrepancy are unclear. It might be the result of a species difference or might be caused by the high $(300 \mathrm{mg} / \mathrm{kg})$ dose of AMT we used. Nevertheless, an average of $5 \mathrm{~h}$ of AMT treatment did not produce hyperventilation. A decrease in $\dot{\mathrm{V}}_{2}$ after AMT was observed, but this decrease was accompanied by a parallel decrease in $\dot{V} E$, resulting in a constant $\dot{\mathrm{VE}}: \dot{\mathrm{VO}}_{2}$ ratio and an unchanged $\mathrm{Pa}_{\mathrm{CO}_{2}}$. These data do not rule out the possibility of a direct involvement of catecholamine metabolism in the neuronal control of ventilation. It is conceivable, for instance, that the elevated 5HT levels reflect an increased serotonergic inhibition of ventilation which offsets a drive for hyperventilation because of the reduction of catecholamine metabolism.

The results of the previous experiments lead to the tentative conclusion that a reduction in 5HT biosynthesis produces hyperventilation. This implies that 5HT-mediated neuronal pathways normally function to inhibit ventilation. 5-Hydroxytryptophan - the product of tryptophan hydroxylase, the enzyme inhibited by PCPA - was used in an experiment (data not tabulated) that lends weight to this hypothesis. Five rats were treated with PCPA as described. After $2 \mathrm{~d}$ they were hyperventilating with a $\mathrm{Pa}_{\mathrm{CO}_{2}}$ reduced by 6.2 torr below pre-PCPA levels $(P<0.01)$. $1 \mathrm{~h}$ after these hyperventilating rats were given 30 $\mathrm{mg} / \mathrm{kg}$ 5-hydroxytryptophan i.p., their $\mathrm{Pa}_{\mathrm{CO}_{2}}$ increased 1.4 torr $(P<0.05)$. Whole brain analysis showed that the NE, DA, and 5HT levels of these rats were not different from paired controls. Thus, specific repletion of serotonin by its metabolic precursor partially alleviated a hyperventilation of $2 \mathrm{~d}$ duration. The fact that the hyperventilation was only partially returned to normal may be the result of an inherent ventilatory inertia not unlike the observed acute incomplete return after long-term hyperventilation produced by other stimuli such as chronic exposure to hypoxia, chronic acid-base derangements, or prolonged voluntary hyperventilation (14).

The hypothesis that the hyperventilation observed was specifically related to serotonin depletion was further strengthened by the use of the drug 6fluorotryptophan (6-FT). 6-FT, like PCPA, works by inhibiting tryptophan hydroxylase (9). However, 6-FT seems to be more specific than PCPA, because $4 \mathrm{~h}$ after treatment with 6-FT whole rat brain levels of NE and DA were unchanged, whereas $5 \mathrm{HT}$ was reduced by $40 \%$. This alteration in $5 \mathrm{HT}$ metabolism produced a hyperventilation reflected by an almost 6-torr decrease in $\mathrm{Pa}_{\mathrm{CO}_{2}}$ and an increase in the $\dot{\mathrm{VE}} \mathbf{\mathrm { VO }}_{2}$ ratio. 6-FT differed from other drugs that produced hyperventilation because 6-FT treatment resulted in a decreased $\dot{\mathrm{VO}}_{2}$. VE was also slightly lower after 6-FT because of an approximate $30 \%$ decrease in breathing frequency and an increase in tidal volume of about $25 \%$.

Para-chloroamphetamine (PCA) specifically depletes central nervous system serotonin via mechanisms which include the inhibition of tryptophan hydroxylase, the release of 5HT stores, and a neurotoxic effect on 5HT-containing neurons. Therefore, PCA has a more rapid and longer-lasting action than the previously used drugs, PCPA and 6-FT (6). $2 \mathrm{~d}$ after PCA treatment, rat whole brain levels of $\mathrm{NE}$ and DA were unchanged although $5 \mathrm{HT}$ levels were reduced by over $50 \%$. This alteration in serotonin metabolism produced a significant sustained hyperventilation as shown by a $30 \%$ increase in tidal volume, an increase in the $\dot{\mathrm{VE}}: \dot{\mathrm{VO}}_{2}$ ratio, a 5-torr drop in $\mathrm{Pa}_{\mathrm{CO}_{2}}$ and a 2.6$\mathrm{meq} / \mathrm{liter}$ fall in $\left[\mathrm{HCO}_{\overline{3}}\right] \mathrm{a}$. Of the pharmacological agents that induced hyperventilation, PCA was unique in also producing an increased $\dot{\mathrm{V}}_{2}$.

Up to this point we have presented data showing that in rats, four different pharmacological agents that alter brain serotonin metabolism by a range of different mechanisms, all result in a substantial hyperventilation.

Finally, we examined the effect of 5,7-DHT on ventilation. Unlike reserpine, PCPA, AMT, 6-FT, and PCA, 5,7-DHT does not readily cross the blood-brain barrier. Thus, in order for 5,6-DHT to have its effect, it must be injected into the cerebrospinal fluid within the ventricles of the brain. 5,7-DHT is thought to act by being taken up by monoamine-containing neurons where it produces long-term cytotoxicity. Desipramine blocks the uptake process of catecholamine-containing neurons, therefore 5,7-DHT given to rats pretreated with desipramine produces specific lesions in 5HTcontaining neurons and a reduction in overall brain levels of 5HT (15). In our rats, 5,7-DHT following pretreatment with desipramine produced a $60 \%$ reduction in whole brain $5 \mathrm{HT}$, a slight reduction in 
whole brain DA, and a small increase in whole brain $\mathrm{NE}$ relative to control rats given $20 \mu \mathrm{l}$ of the carrier solution intracerebroventricularly. Surprisingly, this treatment resulted in a mild, but significant, hypoventilation as indicated by an increase in $\mathrm{Pa}_{\mathrm{CO}_{2}}$ of over 2 torr.

We visualize three possible explanations for the discrepancies between 5,7-DHT treatment and the other serotonin-altering drug regimens shown in Table II.

First, it is possible that reserpine, PCPA, 6-FT, and PCA nonspecifically alter some unidentified neurotransmitter which is not affected by 5,7-DHT. There is no direct evidence for the existence of this unknown neurotransmitter.

Second, the regulation of ventilation is controlled by both central nervous system and peripheral neuronal inputs. Most of the pharmacological agents we used were administered intraperitoneally. These drugs can cross the blood-brain barrier and alter whole brain levels of monoamines; in addition, they probably alter monoamine metabolism at peripheral sensory sites (such as the carotid bodies or vagally innervated receptors). In contrast, 5,7-DHT does not cross the blood-brain barrier and must be administered intracerebroventricularly. It could be that alteration of serotonin metabolism at sites outside the central nervous system (by reserpine, PCPA, 6-FT, and PCA) produces an alteration in ventilation, and brain serotonin metabolism is not directly related to the control of breathing. We have not, as yet, been able to devise an experiment that directly examines this possibility.

Third, a pre- or postsynaptic supersensitivity for serotonin has been shown after 5,7-DHT-induced destruction of nerve terminals (16). There is circumstantial evidence that this supersensitivity could provide a mechanism through which steady-state serotonin-mediated neuronal interactions would be unimpaired even though the overall level of serotonin is greatly reduced. We know of three experimental systems - the development of tolerance to phenobarbital (17), the initiation and maintenance of slowwave sleep (18), and our present work - in which a pharmacological reduction of serotonin metabolism has been linked to a physiological function, and where 5,7-DHT treatment has produced contradictory results. We believe that the action of 5,7-DHT does not cause a reduction in serotonin-mediated neuronal transmission. Thus, even though 5,7-DHT reduces whole brain levels of serotonin, steady-state inhibition of ventilation by serotonergic nerve transmission (as demonstrated by the other pharmacological agents listed in Table II) is unimpaired after 5,7-DHT treatment.

Although the studies we report are pharmacological, it is our proposal that some serotonin-mediated nerve transmissions might function under physiological conditions to inhibit the central nervous system output that controls the muscles involved in breathing. A reduction in serotonin biosynthesis would therefore result in hyperventilation. The site of these serotonergic pathways has not been defined, but probably originates within the raphe nuclei of the brainstem (19).

\section{ACKNOWLEDGMENTS}

We thank Paul Branch, Monique Sabin, Kathy Henderson, Tom Mattice, Mary Lutz, Rob Rhyner, and Dean Faber for technical assistance throughout the data gathering period, and Professor Frank Siegel for pharmacological consultations.

This and related research is supported by U. S. Army contract DAMD 17-77-C-7006; U. S. Public Health Service research career development award HL00438 to Dr. Olson; and U. S. Public Health Service research career development award HL00149 to Dr. Dempsey.

\section{REFERENCES}

1. Flórez, J., G. Delgado, and J. A. Armijo. 1972. Adrenergic and serotonergic mechanisms in morphine-induced respiratory depression. Psychopharmacologia. 24: 258274.

2. Armijo, J. A., and J. Flórez. 1974. The influence of increased brain 5-hydroxytryptamine upon the respiratory activity of cats. Neuropharmacology. 13: 977-986.

3. Severinghaus, J. W., and C. P. Larson, Jr. 1965. Respiration in anesthesia. Handb. Physiol. 2: 1219-1264.

4. Derenne, J-P., J. Couture, S. Iscoe, W. A. Whitelaw, and J. Milic-Emili. 1976. Occlusion pressures in man rebreathing $\mathrm{CO}_{2}$ under methoxyflurane anesthesia. J. Appl. Physiol. 40: 805-814.

5. Olson, E. B., Jr., and J. A. Dempsey. 1978. Rat as a model for human-like ventilatory adaptation to chronic hypoxia. J. Appl. Physiol. 44(5): 763-769.

6. Sanders-Bush, E., and V. J. Massari. 1977. Actions of drugs that deplete serotonin.Fed.Proc. 36(8): 2149-2153.

7. Jequier, E., W. Lovenberg, and A. Sjoerdsma. 1967. Tryptophan hydroxylase inhibition: the mechanism by which $p$-chlorophenylalanine depletes rat brain serotonin. Mol. Pharmacol. 3: 274-278.

8. Moore, K. E. 1966: Effects of $\alpha$-methyltyrosine on brain catecholamines and conditioned behavior in guinea pigs. Life Sci. 5(1): 55-65.

9. McGeer, E. G., D. A. V. Peters, and P. L. McGeer. 1968. Inhibition of brain tryptophan hydroxylase by 6-halotryptophans. Life Sci. 7(12): 605-615.

10. Sanders-Bush, E., J. A. Bushing, and F. Sulser. 1975. Long-term effects of $p$-chloroamphetamine and related drugs on central serotonergic mechanisms. J. Pharmacol. Exp. Ther. 192(1): 33-36.

11. Björklund, A., H. G. Baumgarten, and A. Rensch. 1975. 5,7-Dihydroxytryptamine: improvement of its selectivity for serotonin neurons in the CNS by pretreatment with desipramine. J. Neurochem. 24: 833-835.

12. Sasa, S., and L. Blank. 1977. Determination of serotonin and dopamine in mouse brain tissue by high performance liquid chromatography with electrochemical detection. Anal. Chem. 43(3): 354-359.

13. Spector, S., A. Sjoerdsma, and S. Udenfriend. 1965. Blockade of endogenous norepinephrine synthesis by 
$\alpha$-methyltyrosine, an inhibitor of tyrosine hydroxylase. J. Pharmacol. Exp. Ther. 147: 86-95.

14. Dempsey, J. A., H. V. Forster, N. Gledhill, and G. A. doPico. 1975. Effects of moderate hypoxemia and hypocapnia on CSF $\left[\mathrm{H}^{+}\right]$and ventilation in man. J. Appl. Physiol. 38: 665-674.

15. Gerson, S., and R. J. Baldessarini. 1975. Selective destruction of serotonin terminals in rat forebrain by high doses of 5,7-dihydroxytryptamine. Brain Res. 85: 140145.

16. Stewart, R. M., J. H. Growdon, D. Cancian, and R. J. Baldessarini. 1976. 5-Hydroxytryptophan-induced myo- clonus: increased sensitivity to serotonin after intracranial 5,7-dihydroxytryptamine in the adult rat. Neuropharmacology. 15: 449-455.

17. Lyness, W. H., and M. J. Mycek. 1976: The role of cerebral serotonin $(5 \mathrm{HT})$ in the development of tolerance to phenobarbital (PB). Fed. Proc. 37: 861A. (Abstr.)

18. Jouvet, M. 1969. Biogenic amines and the states of sleep. Science (Wash. D. C.). 163: 32-41.

19. Fuxe, K., and G. Jonsson. 1974. Further mapping of central 5-hydroxytryptamine neurons: studies with the neurotoxin dihydroxytryptamines. Adv. Biochem. Psychopharmacol. 10: 1-12. 